\title{
Practice of Moral Education in the Context of Srimad Bhagavad Gita with Reference to the Concept of Self and Pedagogy
}

\author{
Paromita Das
}

\section{Abstract}

\begin{abstract}
Values are ultimately personal; the implicit message is that there is no right or wrong value. Schools have a moral ethos embodied in rules, rewards and punishments, dress codes, honour codes, relationships, styles of teaching, extracurricular activities, art, and in the expression of respect. Schools convey to children what is expected of them, what is normal, what is right and wrong. It is often claimed that values are caught rather than taught; through their ethos, schools socialise children into patterns of moral behavior. The present study analyses the practice of moral education as described in the Gita with reference to concept of the Self and pedagogy and how the understanding of the Self and pedagogy can help the teachers in improving their character and pedagogical practices in imparting the real form of education to the children for both present and future.
\end{abstract}

Keywords: Moral, Action, Community, Yoga, Practices

\section{Introduction}

Psychology is a scientific discipline that essentially deals with the fundamental understanding of human behaviour. While the extremely controversial and contentious discipline has often been juxtaposed with "common sense", in the terms of a lay person or

\footnotetext{
*Visva-Bharati, Santiniketan, West Bengal, India; prmtds698@gmail.com
} 
common parlance, the discipline along with its long history of illustrative scholars, has developed through the years, generating scientific theoretical paradigms with respect to human behaviour as well as methods for applying those particular paradigms.

Social psychology is one of the sub-disciplines that endeavours to take into cognizance the domain that attempts to understand the manner in which people account for the social dynamics associated with the domain of quotidian events. (Potter \& Wetherell, 1987)

The idea of self is a domain that has intrigued social psychologists and sociologists alike. However, despite the numerous epistemological and ontological key centrality of an aforementioned concept, a plethora of academicians have refrained from arriving at a homogenous definition for the concept of self, thereby, reducing it to the paraphernalia of concepts that can be " never clear", "univocal" plus "straightforward" (Harre, 1997). Therefore, at this juncture a pertinent question can be posited.

What is indicated by the concept of self?

According, to the pioneers of the concept, inclusive of George Herbert Mead, self is defined as an experience of the individual ever since birth; it is a process which takes place in the mind of an individual however, "it is only through the development of a self makes the person realise that the experience is its own" (Mead, 1934).

Having argued with respect to the aforementioned context, another pertinent question can be posited at this juncture. How is the self social? Myriad perspectives can be attributed to the manner in which self has been defined by numerous illustrious social psychologists, anthropologists as well as sociologists alike.

With pertinence to its theoretical as well as practical consequences, the solution to the aforementioned question can be titled as solitary of the primarily contest and important debates in the psychology of self. In an attempt to 'localise' the self and decipher its complicated existence, several academicians have pointedly indicated towards the distinct domains of biology, evolution and, 
more specifically genes. By treating the person in the social world just as any other species in its habitat (Stevens \& Wetherell, 1996), the radical biologic argument (Reicher, 2004) achieved an embodiment and de-socialisation of the self. Since human agency depends on brain processes (Toates, 1996), determinism and universalism contributes in construing the self comes as a module which is 'justified' with respect to the two adaptation purposes, namely, depositing social feedback and understanding the intentions and behaviours of others (Forgas \& Williams, 2002).

Among the rubric of explanations put forth by various scholars, attempting to delineate the underpinnings of the self, the predominantly significant definition of the same has been undertaken by George Herbert Mead (1934), the author the seminal sociological research exposition, The Mind, Self and Society. Mead's investigation of the concept is embedded in the substratum of symbolic interactionism and takes advent from the inter-related acts or conversation of gestures (Mead, 1934). Through these activities, interactions attitudes are expressed and the social responses are adjusted. When conceived in its symbolic nature, the conversation of gestures is explicative of the development of human intelligence and, ultimately, of society and knowledge. The mind and the self arise through social experience and in this process, the dissonance of language play a key part through facilitating co-operation, communication and transmission of culture.

To trace back the idea of the self in philosophy it is said that it covers a central role in most philosophical branches. For instance, in metaphysics, the self has been seen as the starting point of inquiry (both in the empiricist and rationalist traditions) or as the entity whose investigation is most deserving and challenging (Socratic philosophy). In ethics and political philosophy, the self is the key concept to explain freedom of the will as well as individual responsibility (Borghini, 2017).

This perspective on the topic will have crucial consequences for the centuries to come (Borghini, 2017). Thus, having rudimentarily gained a brief idea of the concept of self, one can now delve into briefly defining the idea of pedagogy whilst undertaking an interrelation of the concepts of self and pedagogy, and lastly the 
understanding of educational aspects of Bhagwad Gita with reference to the "self-concept" as well as pedagogy.

\section{Pedagogy: theoretical contextualisation}

What is constituted by the term "pedagogy"?

Put in a nutshell, David Trend in his illuminating research exposition titled as, "Cultural Pedagogy: Art, Education and Politics"(Trend, 1992) as a teaching technique adopted to impart the transmission of knowledge and skills. In other words, pedagogy can be conceptualised as the systematic production of knowledge (Trend, 1992), identities and values. However, while delving further with respect to specifics of pedagogy, it can be stated that rather than being a simplistically a give and take teaching process, the concerned author pulls the aforementioned concept out of its ghettoisation by arguing that pedagogy encompasses a practice that enshrines cultural and political production processes (Trend, 1992) which is intrinsically embedded in the construction of knowledge, subjectivities and social relations.(Trend, 1992) Pedagogy is therefore akin to the concept of self represents a cultural as well as a social phenomenon (Trend, 1992).

Raja-vidya raja-guhyam

Pavitramidamuttamam

Pratyaksavagamamdharmyam

Su-sukhamkartumavyayam" - (chapter 9, Verse 2)

This could be transliterated as the following:

This knowledge is the king of education

The most secret of all secrets

It is the purest knowledge, and because it gives

direct perception of the self by realisation

It is the perfection of religion

It is everlasting, and it is joyfully performed. 
With respect to the aforementioned quotation, it can be said that the valuable Hindu epic literature is held by many as the gospel of transcendental education, an education that empowers the self with respect to realising its inimical importance. The epic in question furthermore propounds a form of education that is far removed from the material education propagated by the West.

Gita posits that the actual meaning of education as receiving virtual knowledge but the question arises - 'what is virtual knowledge'? Whenever we see or we feel the universe in diversity and God exists everywhere"(Ramachandran Sharma \& Ramachandran, 2015). It is further elaborated as "true knowledge is that which teach us to see God in each soul" (Ramachandran Sharma \& Ramachandran, 2015). It has also been indicated by the Gita, the supreme form (Ramachandran Sharma \& Ramachandran, 2015) of all the purest knowledge and its essence that knowledge has been derived by undertaking an in-depth study of the Vedasas well as the various versions of the Upanishads. The Bhagavad Gita specially stresses on the importance of the soul (Sharma and Ramachandran, n.d.) with respect to receiving appropriate education. The Gita also deduced that according to the supreme governing force, the human body is perishable but the soul is not perishable (Ramachandran Sharma \& Ramachandran, 2015). The very cognizance of the aforementioned statement stresses upon the fact that such an above stated form constitutes the confidential part (Ramachandran Sharma \& Ramachandran, 2015) of knowledge; simply knowing that the pure soul is different from the body which is going to be finished (Ramachandran Sharma \& Ramachandran, 2015), the soul remains same and becomes immortal (Ramachandran Sharma \& Ramachandran, 2015).

The Bhagwad Gita enshrined Lord Krishna as the primary teacher who through his sermons and advices doled out life teachings with respect to a plethora of domains, including that of how education should be undertaken and what should be the pedagogy. The essence of the same is that as per the idea of Gita the human child cannot be viewed as a tabula rasa or a blank slate. Contrarily, a child inherits certain tendencies, instincts, as well as the propensities of character, mental dispositions etc. from his past life. According to the epic, parents are solely the providers of the 
child's body; however in contrast, his physical apparatus and soul's doing is his own. This explains individual differences. (Ramachandran Sharma \& Ramachandran, 2015) The Bhagavad Gita then undertakes a reconciliation of the parameters such as the metaphysics and physics, nivritti (Ramachandran Sharma \& Ramachandran, 2015) and pravrtti, psychical entity, and heredity and environment (Ramachandran Sharma \& Ramachandran, 2015) of men and dispenses the principles of education there by indicating that education is the spiritual-social necessity. Education thus according to the propositions of the Bhagwad Gita is a value and its edifice cannot be built on sand.

Furthermore, according to the Bhagwad Gita, the preferred methods of pedagogy that ought to be adopted can be rigidly put as the conversational method (Ramachandran Sharma \& Ramachandran, 2015), question-answer method (Ramachandran Sharma \& Ramachandran, 2015), demonstration method, (Ramachandran Sharma \& Ramachandran, 2015) contemporary method (rational analysis with proper analysis), and pedagogy of practice (Ramachandran Sharma \& Ramachandran, 2015).

The educational aspects of the rich Bhagwad Gita with reference to the concepts of self and pedagogy can pave the way for an exhaustive research in the domain of education studies. Also taking into cognizance such a line of thought, the next section will discuss the nature and scope of the problem statement of the prospective study.

\section{Problem statement}

The teacher must teach his/her subject with great competence but when the issue of judgement is involved, he/she should let the student free as Arjun was finally left to decide himself whether to fight or not. The concept of the teacher in the Gita is that he/she must be most balanced. The true teacher not only teaches truth but also demonstrates it. In short, the teacher is vigilant to keep the soul and body of his student as well as his own together. The student, according to the Gita, is not a disciple but a learner. But the first and the last characteristic of an ideal student are to surrender before the teacher accepting his ignorance of the subject 
he/she wants to know. Genuineness, humanity, obedience, and faith in his teacher are the essential characteristics of a good learner. $\mathrm{He} / \mathrm{she}$ must also possess an intense urge to know without which he/she will not be able to understand what the teacher gives. Humility, obedience, faith among other characteristics towards the teacher implies that the student should be virtuous. The student, according to Gita, must shun three great vices- Kama, Krodh and Lobha in his/her personality. Obedience means respect to the teacher; however, it does not mean the foolish obedience in which everything is accepted by the student blindly; however, "the eager intellect of the student must be satisfied" (Sharma \& Ramachandran, n.d, pp. 10571).

The aforementioned quotation delineates the favoured path of education be it in terms of the ideal teacher, the ideal student, the apt nature of relationship that should be maintained between them in a classroom setup.

At this juncture a poignant question can be raised in common parlance. Why consult the meta-educational virtues of Bhagwad Gita in the contemporary epoch of meritocratic and materialistic and predominantly west influenced education setup? Is not the much revered Hindu epic authored during the primordial times, out-dated as well as irrelevant in a majoritarian manner?

However paradoxical, the questions itself provide an answer to their interrogations. The very superficiality of the meritocracy as well as the materialism of the contemporary education provided in almost all educational institutions are the reason why transcendental as well as philosophical parameters espoused by the Bhagwad Gita are relevant so that an individual present in a societal setting gains value oriented education (Steiner, 2009), which can develop himself/herself in par with the realisation of his self. In conclusion, it can be stated through the lens of education, meaning of education, aims of education, importance of education, learning materials, pedagogy, curriculum, motivational techniques, assessment practice, and roles of learner and teacher can be found and interpreted by and through a deeper reading of the Bhagavad Gita. Therefore, the Bhagavad Gita (Steiner, 2009) can be taken as an educational philosophy, since it universally 
encompasses the plethora of components of an educational philosophy.

\section{Aims and objectives}

Evaluating the practice in moral education in Bhagavad Gita with reference to concept of self and pedagogy is the aim of the paper.

The objectives are the following:

- The present study primarily examines the need of moral education in Bhagavad Gita with reference to the concept of self as well as pedagogy in the contemporary Indian public school classroom set up.

- The study will aim to examine the applicability of the moral education of Bhagavad Gita with reference to concept of self and pedagogy in the contemporary Indian public school classroom set up.

- The study will endeavour to delineate the variable of intellect and assess the extent to which it has been affected by adopting the educational philosophy adopted in the contemporary Indian public school set up.

\section{Literature review}

This section essentially concerns itself with a detailed examination of the numerous studies that have been conducted by specialists in the past several years in the current area of interest.

The succeeding literature would majorly deal with practising moral education of Bhagavad Gita with special reference to the concepts of self and pedagogy, its effects as well as the related variables such as a detailed understanding of the various perspectives on the concept of self as well the manner in which pedagogy is an intrinsic part of the socio-political rubric.

Firstly, Ramachandra Manickam and Bhawna Ramachandran Sharma (2015) in their illuminating research endeavour titled as "Need of Bhagavad Gita Concepts in the Present Scenario of Professional Education" discusses the current populations' hyper awareness with respect to the educational theories and thoughts 44 
developed in the West and how it juxtaposes with inadequate information about one's own historical and cultural thoughts in relation to education, despite their importance and comprehensiveness. In the Bhagavad Gita, the researcher deduced that some of the basic components of educational philosophy are present. Among the various aspects of educational thoughts, this paper deals with the interpretation of the meaning of education that can be found in the Bhagavad Gita. Interpretation of a comprehensive meaning of education consisted within the Bhagavad Gita can contribute to inspire academicians to look behind the curtain of history for searching valuable knowledge. Thus, the aforementioned research exposition establishes the need for applying the aforementioned epic in the present day Indian classrooms.

Secondly, Glăveanu (2010) in his enriching article titled as, "The Self in Social Psychology: Towards New Perspectives" discuss the vast labyrinth of ideas that can be encompassed in the understanding of the concept of Self. This essay starts by reviewing definitions of the self as well as the main problems psychologists are confronted with when theorising the self. The researcher associated with the present study argues in favour of the vision of the self as being a social structure that both tendencies to "individualise" and "discursify" fail to acknowledge the intersubjective nature of the self and its genesis within me - other relations. This particular approach will be further developed by connecting the self to the social context of representations, attributions and culture. In the end, the notion of "synergetic self" will be introduced and developed with an emphasis on its dynamic, transformative, emergent and creative dimensions.

Another significant research exposition titled as "Performance Theories in Education: Power, Pedagogy, and the Politics of Identity" (Alexander, Anderson \& Gallegos, 2004) undertakes path breaking research by presenting a range of approaches in undertaking the comprehension of the role, function, impact, and presence of performance in education. It is a definitive contribution to a beginning dialogue on the manner in which performance, as a theoretical and pragmatic lens, can be used to view the processes, procedures, and politics of education. 
As can be gauged from the detailed literature review, one can identify the thematic essence of the prospective research which will essentially attempt to examine the dynamics of the educational aspects of Bhagwad Gita, contextualising it in pertinence to its application with reference to the concepts of self and pedagogy in the present day Indian public classroom set up.

\section{Research methodology}

This section undertakes an in-depth explanation of the research methods that the researcher will espouse to use in the prospective study. It would be prudent at this juncture to delineate certain components of research methodology which will propel a better understanding of the dynamics of the research to be undertaken in the prospective study.

Research paradigm can be understood as, "the underlying assumptions and intellectual structure upon which research and development in a field of inquiry is based"(Kuhn, 1962, 1970).

Research models, encompassed in any scientific discipline, would fall into two broad categories of classification. One, positivistic research model and two, hermeneutic research model (Creswell, 1994).

Hermeneutic or interpretivist research model is what the researcher essentially espouses to use in the due course of the prospective study. The hermeneutic or the interpretivist research model as the name suggests, relegates itself to the "craftsmanship or art of scriptural understanding" (Thomas, Silverman \& Nelson, 2015).

The researcher will use content analysis since a major part of the research is about interpreting the educational aspects present in Bhagwad Gita with reference to the concepts of self as well as that of pedagogy, the idea of analysing thematically the various references based on Gita will enrich the research with apt outcomes.

The researcher would also depend on Participant Observation. Through this qualitative method of data collection, the research would be taken to the two strata of respondents; the students and 
the teachers and their inculcation of the educational elements of the Indian epic and its impact on their self as well as pedagogy will be studied therein. This would be achieved by simply observing or participating to a certain extent in the everyday activities of the community under study.

Two limitations of the study would be that this project is limited to the interpretation of the practice in moral education in Bhagavad Gita with reference to only two concepts, that of self and pedagogy and is concerned with the Indian public school set up.

\section{Proposals for implementation in the education system}

1. To develop virtuous knowledge among the students by removing their ignorance and focussing them to perform their duties.

2. To develop and effect sublimation of personality in students and learners to be able to motivate themselves towards the right path by being able to discriminate between good and evil.

3. To be able to co-ordinate between the individual and social aim in students by being able to sacrifice the individual freedom which often creates confusion in life and to give preference to take up social responsibility.

4. To develop the inner-consciousness among the students/ individuals through meditation and concentration so that the sense of self-duty is awakened without any compulsion

5. To develop intellectual and logical abilities through logical reasoning so that the individuals or students can make their own decisions in the face of alternatives.

6. To develop an attitude among the students that there is nothing greater than performing one's duties. Real happiness lies in establishing a balance between one's rights and duties.

7. To include both types of knowledge in the curriculum as mentioned in the Bhagavad Gita, that is AparaVidya (Knowledge about the material world) and Para Vidya 
(Knowledge of the Individual Self and Supreme Self). Weightage should be given to the ParaVidya which imparts knowledge about spiritualism of life which alone can give eternal peace to man. Mostly the Apara Vidya is given weightage in the form of all the subjects in disciplines like arts, science and engineering which results in the predominance of the acquisition of worldy wealth of all types at the utter neglect of spiritual realm.

8. The noblest moral education that can be given to the youth of today is to perform one's duties without taking into consideration its outcome and thereby to overcome any worldly attachment to enable them to reach the highest moral ideal of education.

\section{Conclusion}

The present study is an investigation to find out the importance and relevance of moral education and its practice in the Indian school system, the trends and to what extent the various features of this education is followed and how. This kind of study is helpful for the teachers, students or younger generation and administrators and policy makers because this Holy Scripture is full of virtuous lessons and positivity especially for the individual life and society. It is a hand-book of Indian culture and as well as universal in its application.

\section{References}

Alexander, B. K., Anderson, G. L., \& Gallegos, B. (2004). Performance theories in education: power, pedagogy, and the politics of identity. Routledge.

Creswell, J .W. (1994). Research design: qualitative and quantitative approaches. Sage Publications: London.

Glăveanu, V. (2010). The self in social psychology: Towards new perspectives. Revista de psihologie, 56(3-4), 269-283.

Goffman, E. (1978). The presentation of self in everyday life. Harmondsworth.

Harré, R. (1997). The singular self: An introduction to the psychology of personhood. Sage: USA. 
Kuhn, T. (1970). The structure of scientific revolutions. Chicago: University of Chicago Press.

Mathur, D. C. (1974). The concept of action in the Bhagvad-Gita. Philosophy and Phenomenological Research, 35(1), 34-45.

Mead, G. H. (1934). Mind, self and society. Vol. 111. University of Chicago Press: Chicago.

Potter, J., \& Margaret W. (1987). Discourse and social psychology: beyond attitudes and behaviour. Sage: USA.

Ramachandran Sharma, B., \& Ramachandran, M. (2015). Need of Bhagavad Gita concepts in the present scenario of professional education. International Journal of Applied Engineering Research, 10(11), 10570-10574.

Steiner, R. (2009). The Bhagavad Gita and the west: The esoteric significance of the Bhagavad Gita and its relation to the epistles of Paul. Vol. 142. Steiner Books.

Stevens, R., \& Wetherell, M. (1996). The self in the modern world: drawing together the threads. In R. Stevens (ed.), Understanding the self, pp. 339-369. London: Sage.

Thomas, J. R., Silverman, S., \& Nelson, J. (2015). Research methods in physical activity, 7E. Human Kinetics: USA.

Toates, F. (1996). The embodiment of the self: A biological perspective. In R. Stevens (ed.), Understanding the Self, pp. 35-88. London: Sage.

Trend, D. (1992). Cultural pedagogy: art, education, politics. Greenwood Publishing Group. 